\title{
Sintering and microstructural investigation of gamma-alpha alumina powders
}

\author{
Emre Yalamaç $^{\mathrm{a}, *}$, Antonio Trapani ${ }^{\mathrm{b}}$, Sedat Akkurt ${ }^{\mathrm{c}}$ \\ a Materials Engineering Department, Celal Bayar University, Muradiye Campus, 45140 Manisa, Turkey \\ ' ${ }^{\mathrm{b}}$ Ingegneria “Enzo Ferrari" Department, Università degli Studi di Modena e Reggio Emilia, Strada Vignolese 905, 41125 Modena, Italy \\ ${ }^{\mathrm{c}}$ Mechanical Engineering Department, Izmir Institute of Technology, 35430 Izmir, Turkey
}

\section{A R T I C L E I N F O}

\section{Article history:}

Received 29 December 2013

Received in revised form

7 February 2014

Accepted 11 February 2014

Available online 26 March 2014

\section{Keywords:}

Alpha-gamma

Alumina

Phases

Densification

Sintering

\begin{abstract}
A B S T R A C T
Sintering behaviors of commercially available alumina powders were investigated using constantheating rate dilatometric experiments. Each powder had different proportion of alpha/gamma alumina. Densification behaviors of powders were studied up to $1600{ }^{\circ} \mathrm{C}$ with three different heating rates of $1,3.3$ and $6.6{ }^{\circ} \mathrm{C} / \mathrm{min}$. Compacts of different gamma content alumina powders exhibited systematic anomalous second peaks in the densification rate curves at certain heating rates and temperatures. At $3.3^{\circ} \mathrm{C} / \mathrm{min}$ heating rate experiments, densification curves of $10 \%$ gamma phase alumina powder compacts reached a plateau after $1450{ }^{\circ} \mathrm{C}$, and did not increase any further at higher temperatures. This phenomenon was double checked to understand powder behavior during sintering. $10 \%$ gamma phase alumina powder compacts showed the highest density for each heating rate. It reached $94 \%$ theoretical density with $1{ }^{\circ} \mathrm{C} / \mathrm{min}$ heating rate. But $20 \%$ gamma phase alumina powder compacts had the finest grain size of about $1.40 \mu \mathrm{m}$. Final density and porosity of compacts were also tested by image analysis and the results were coherent with Archimedes results.
\end{abstract}

Copyright $\odot$ 2014, Karabuk University. Production and hosting by Elsevier B.V. All rights reserved.

\section{Introduction}

Alpha alumina $\left(\alpha-\mathrm{Al}_{2} \mathrm{O}_{3}\right)$ has unique mechanical, electrical, and optical properties therefore it is utilized in many areas of modern industry. Properties of ceramic materials are governed by their microstructures. To obtain superior microstructures, refining $\alpha$ $\mathrm{Al}_{2} \mathrm{O}_{3}$ processing technique is of great interest. Transition alumina phases have recently attracted much attention because of their intrinsically nanocrystalline nature and because they can be synthesized by a variety of techniques [1]. Gamma alumina $\left(\gamma-\mathrm{Al}_{2} \mathrm{O}_{3}\right)$ is the most common transition alumina phase. When $\gamma-\mathrm{Al}_{2} \mathrm{O}_{3}$ is heated, it undergoes a series of polymorphic transformations from a highly disordered cubic close packed lattice to the more ordered cubic close packed $\theta-\mathrm{Al}_{2} \mathrm{O}_{3}$. When heated to $\approx 1200{ }^{\circ} \mathrm{C}, \theta-\mathrm{Al}_{2} \mathrm{O}_{3}$ undergoes a reconstructive transformation by nucleation and growth, where the oxygen atoms rearrange into a hexagonal close packed structure to form thermodynamically stable $\alpha-\mathrm{Al}_{2} \mathrm{O}_{3}[1,2]$.

$\gamma-\mathrm{Al}_{2} \mathrm{O}_{3} \rightarrow \delta-\mathrm{Al}_{2} \mathrm{O}_{3} \rightarrow \theta-\mathrm{Al}_{2} \mathrm{O}_{3} \rightarrow \alpha-\mathrm{Al}_{2} \mathrm{O}_{3}$

\footnotetext{
* Corresponding author. Tel.: +90 236 2012404; fax: +90 2362412143.

E-mail addresses: emre.yalamac@cbu.edu.tr, emreyalamac@gmail.com (E. Yalamaç).

Peer review under responsibility of Karabuk University
}

The $\alpha-\mathrm{Al}_{2} \mathrm{O}_{3}$ phase transformation occurs by nucleation and growth. A low intrinsic nucleation density results in large spacing between nucleation events and the formation of micrometer scale, single crystal $\alpha-\mathrm{Al}_{2} \mathrm{O}_{3}$ grains with dendritic protrusions surrounded by continuous pore channels. The resultant vermicular microstructure requires sintering temperatures $>1600{ }^{\circ} \mathrm{C}$ to reach high densities [3]. To obtain dense, fine-grained $\alpha-\mathrm{Al}_{2} \mathrm{O}_{3}$ at low temperatures, the scale of the vermicular microstructure must be minimized [4].

A number of researchers have attempted to enhance the transformation and the final microstructure of alumina ceramics by using dopants or by seeding [5-7].

The more relevant study, Kim and Kim [8] investigated the effect of phase transformation and dispersion of fine zirconia particle on densification of high purity nanocrystalline alumina. They mixed $\alpha$ alumina with $\gamma$-alumina at different ratios and pressurelesssintered at different temperatures for $3 \mathrm{~h}$ in air atmosphere. According to their study, full densification with fine microstructure for the $10 \% \gamma$-phase dispersed $\alpha$-alumina specimen was achieved by the rapid transformation to $\alpha$-phase and by the zirconia dispersion.

The objective of this investigation, therefore, was to compare the densification behavior by following the densification curves and following the corresponding microstructure evolution of three 
Table 1

Chemical and physical properties of the powders [9].

\begin{tabular}{|c|c|c|c|c|c|c|}
\hline & & CR6 & CR15 & & CR30 & \\
\hline \multicolumn{2}{|l|}{ Present phases } & $100 \% \alpha$ & $90 \% \alpha$ & $10 \% \gamma$ & $80 \% \alpha$ & $20 \% \gamma$ \\
\hline \multicolumn{2}{|l|}{ Ultimate particle size/TEM (nm) } & 400 & 350 & 20 & 300 & 20 \\
\hline \multicolumn{2}{|l|}{ Alpha crystallite size/RD (nm) } & 50 & 45 & - & 40 & - \\
\hline \multicolumn{2}{|l|}{ BET SSA $\left(\mathrm{m}^{2} / \mathrm{g}\right)$} & 6 & 15 & & 26 & \\
\hline \multirow[t]{5}{*}{ Chemical analysis ICP (ppm) } & $\mathrm{Fe}$ & 4 & 4 & & 5 & \\
\hline & $\mathrm{Na}$ & 13 & 13 & & 13 & \\
\hline & $\mathrm{Si}$ & 13 & 13 & & 16 & \\
\hline & $\mathrm{Ca}$ & 3 & 3 & & 2 & \\
\hline & $\mathrm{K}$ & 22 & 22 & & 22 & \\
\hline
\end{tabular}

different commercial aluminas, two of them contained some $\gamma$ $\mathrm{Al}_{2} \mathrm{O}_{3}$ phase and the last one was high purity $\alpha-\mathrm{Al}_{2} \mathrm{O}_{3}$. We hope to elucidate the key mechanism of such gamma to alpha phase transformation assisted densification.

\section{Material and methods}

Three kinds of commercial grade submicron-grained alumina, one of them is $100 \%$ alpha $(\alpha)$ phase (CR6-Baikowski) powder and the second one is $10 \%$ gamma $(\gamma)$ and $90 \%$ alpha-alumina phases (CR15-Baikowski) powder and the last one is $20 \%$ gamma and $80 \%$ alpha alumina phases (CR30F-Baikowski) powder were used. Their designations and some physical, chemical properties are shown in Table 1 . These powders with gamma and alpha alumina phases are not mixtures blended by the authors but are mixedphase commercial products directly obtained from the manufacturer.

Particle size distributions of the powders were analyzed by sedigraph method (Micrometrics Sedigraph III 5120). Specific surface areas of powders were measured by Brunauer, Emmet and Teller (BET) method (Micrometrics Gemini V). Particle morphologies of powders were investigated using SEM (SEM, Philips XL-30S FEG). The present crystalline phases were examined by X-ray diffraction (XRD, Philips X-Pert Pro). The sintering behavior of the powders were investigated by dilatometric method. The powders were uniaxially pressed at $200 \mathrm{MPa}(\phi: 10 \mathrm{~mm})$ and the compacts were sintered in the vertical dilatometer (Linseis L75V) up to $1600{ }^{\circ} \mathrm{C}$ under static air with different heating rates of $1,3.3$ and $6.6^{\circ} \mathrm{C} / \mathrm{min}$. Final densities of the sintered compacts were measured by Archimedes' method (ASTM C373-88). Theoretical density for alumina was taken as $3.987 \mathrm{~g} / \mathrm{cm}^{3}$. To investigate the microstructure of the sintered compacts, specimens were cut from their center and then were polished with fine diamond suspension up to $1 \mu \mathrm{m}$. The polished surfaces were thermally etched at $100{ }^{\circ} \mathrm{C}$ below the

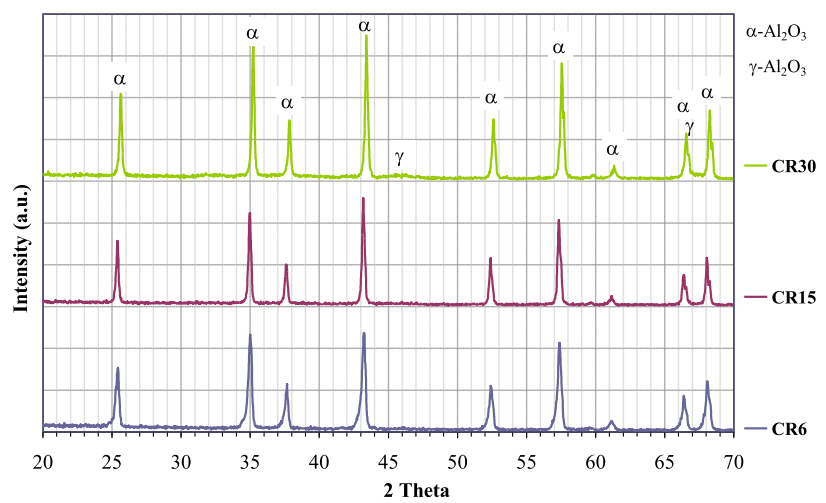

Fig. 1. XRD analysis results of the powders. sintering temperature for $1 \mathrm{~h}$. The polished and thermally etched surfaces were investigated under SEM. The grain size was roughly measured from polished and thermally etched surfaces of sintered alumina ceramics.

\section{Results and discussion}

Fig. 1 shows the XRD results of the raw powders. The peaks for the alpha phase were quite clear and sharp while those of the gamma phase were barely noticeable. The bump at $46^{\circ} 2 \theta$ angle for CR30 sample is visible as this sample contains $20 \%$ gamma phase. An explanation might be that gamma alumina gives a signal of very low intensity compared to alpha alumina.

Specific surface area (SSA) of the powders was measured by the BET method. Both published and measured SSA values of the powders are given in Table 2. Published data were obtained from the producer and may change from lot to lot. Measured SSA values differed slightly from the published value, as expected.

With the sedigraph method it has been possible to investigate the particle size distributions of the powders through the granulometric curves (Fig. 2). Results are shown in Table 3 and were compared with the ones reported by the producer. The accordance between the $D_{50}$ values obtained with this analysis and the one given by the producer were good, in fact the results were very close. It is also important to underline that a significant fraction of the powders were finer than $1 \mu \mathrm{m}$.

Through SEM investigation, powders morphologies and the possible agglomerations were investigated and powder particle size was roughly measured. In Fig. 3 some SEM images of the powders are shown and in Table 4 particle size results are reported.

The analyses on SEM images show some presence of soft agglomerations of the powders (Fig. 3a, c and e). At higher magnification $(100 \mathrm{k} \times) \gamma$-phase was not observed in sample CR6 (Fig. 3b). Presence of $\gamma$-phase alumina (Fig. 3d and f), as indicated by the circles and arrows, was observed in CR15 and CR30 samples. It is also possible to have a rough idea of the differences in the quantity of $\gamma$-alumina among CR15 and CR30. A particular shape of the $\gamma$ alumina powders was mainly vermicular.

Table 5 compares particle diameter results as obtained by different characterization techniques and the data from the producer. Important to be noticed was that there was good accordance between the results obtained with the sedigraph method and SEM images analysis, also compared to the one furnished by the powder producer.

\subsection{Constant heating rates $\left(1,3.3\right.$ and $\left.6.6^{\circ} \mathrm{C} / \mathrm{min}\right)$}

Different sets of samples were prepared to study the three different aluminas. It was decided to select three different heating regimes to analyze the sintering behavior of the powders: Constant Heating Rate $(\mathrm{CHR})$ at $1{ }^{\circ} \mathrm{C} / \mathrm{min}, 3.3^{\circ} \mathrm{C} / \mathrm{min}$ and $6.6^{\circ} \mathrm{C} / \mathrm{min}$, up to $1600{ }^{\circ} \mathrm{C}$

Some codes are used to identify clearly the kind of powder and the heating regime used to sinter the pellet. The designation of the powders and heating rates are shown in Table 6.

Table 2

BET analysis results.

\begin{tabular}{llll}
\hline & CR6 & CR15 & CR30 \\
\hline Measured specific surface area $\left(\mathrm{m}^{2} / \mathrm{g}\right)$ & $4.0 \pm 0.2$ & $12.2 \pm 0.2$ & $21.6 \pm 0.3$ \\
SSA (data from the producer) $\left(\mathrm{m}^{2} / \mathrm{g}\right)$ & 6 & 15 & 26 \\
\hline
\end{tabular}




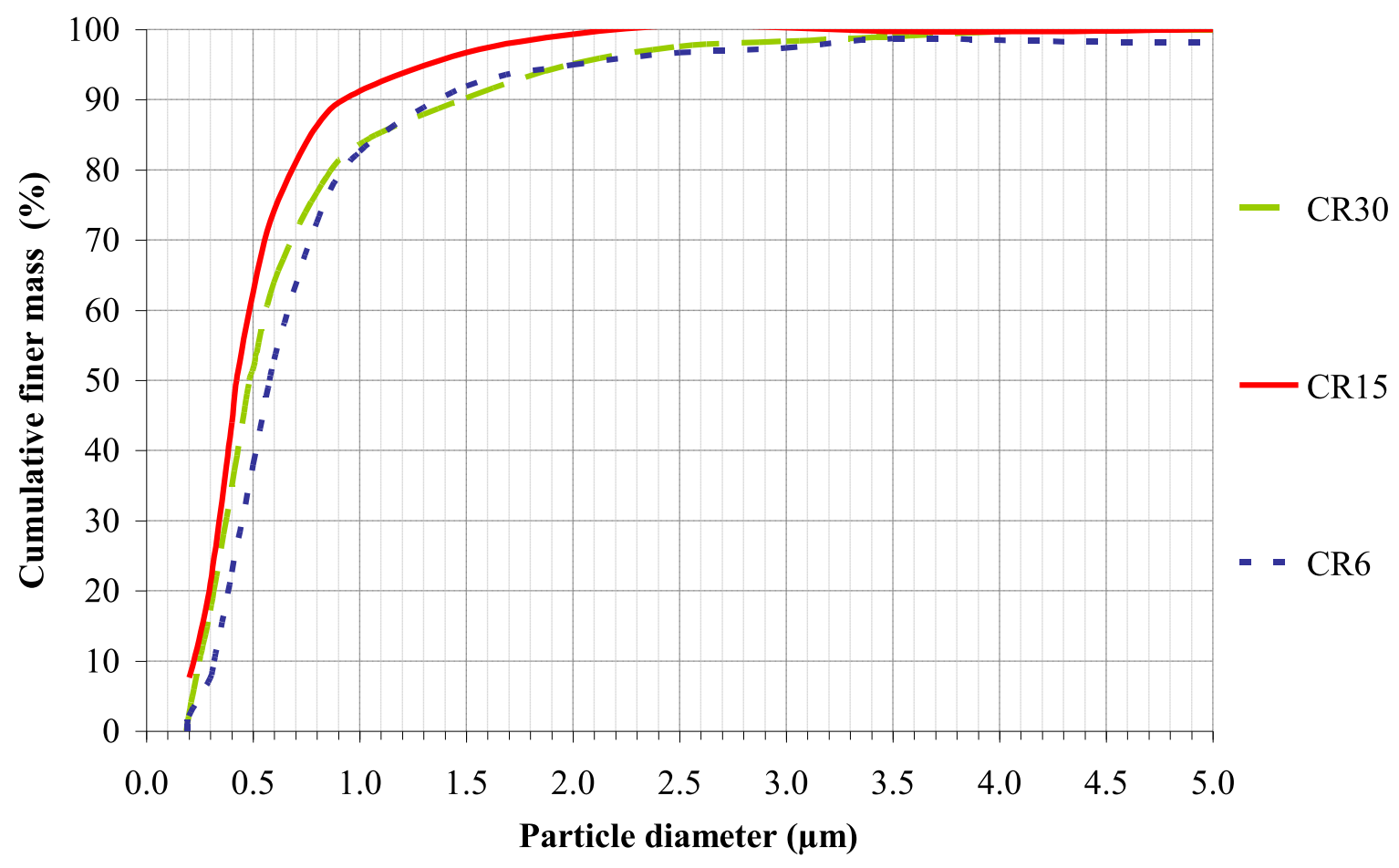

Fig. 2. Particles size distribution curves for alumina powders.

To calculate the relative density, a theoretical density value of $3.987 \mathrm{~g} / \mathrm{cm}^{3}$ was used for pure $\alpha$-alumina, considering that all $\gamma$ phase reacted. Archimede's test results of samples are shown in Table 7. It's important to notice that full density was not reached and all the values are below 95\%. The highest value was obtained by the sample CR15- 1 that reached $94.2 \%$ and the lowest was obtained by the sample CR30-6.6. To see the results more comparatively, the density results are also plotted together in Fig. 4. Up to $10 \% \gamma$-phase content (CR6), the relative densities increases for all heating rates but after $10 \% \gamma$-phase content, the relative densities decrease with increasing content of $\gamma$-phase (CR30). These results were in agreement with the study of Kim and his colleague [8]. These results were attributed to the increase of internal colony porosity.

Starting from these results, it was possible to plot densification and densification rate curves. In particular the attention was focused on the final relative densities of the compacts $(\rho)$ and their temperature derivatives $(\mathrm{d} \rho / \mathrm{d} T)$. Fig. 5 shows relative density and densification rate curves of the powders at $1{ }^{\circ} \mathrm{C} / \mathrm{min}$ heating rate with respect to temperature. Analyzing the graphs, curves show that CR6-1, CR15-1 and CR30-1 relative density present the same trend during the sintering: in particular CR15-1 and CR30-1 trend is so similar that the two curves were almost parallel. This behavior is kept also in the densification rate curves where they are almost overlapped until they reached the maximum speed in densification, at around $1380^{\circ} \mathrm{C}$, while for CR6- 1 this temperature is shifted to a higher value. It's possible, anyway, to notice a difference between CR15-1 and CR30-1, in Fig. 5: in CR30-1, at about $1150{ }^{\circ} \mathrm{C}$, there's a small bump in the densification rate curve, while there's no trace in CR15-1 curve. This is probably caused by the

Table 3

Sedigraph analysis results.

\begin{tabular}{llll}
\hline & CR6 & CR15 & CR30 \\
\hline Measured $\mathrm{D}_{50}(\mu \mathrm{m})$ & $0.58 \pm 0.01$ & $0.42 \pm 0.01$ & $0.48 \pm 0.01$ \\
Data from the producer $\mathrm{D}_{50}(\mu \mathrm{m})$ & 0.6 & 0.4 & 0.4 \\
\hline
\end{tabular}

transformation of $\gamma$-alumina in $\alpha$-alumina that requires the absorption of some energy with the consequent temporary increase in the densification rate.

The relative density and densification rate curves of the powders at $3.3^{\circ} \mathrm{C} / \mathrm{min}$ heating rate with respect to temperature are shown in Fig. 6 . As expected, the density results achieved are lower than the ones obtained with a heating rate of $1^{\circ} \mathrm{C} / \mathrm{min}$, although the trend is similar. The highest value is obtained by CR15-3.3 while the lowest one is by CR6-3.3. According to graphs, CR6-3.3 has got a completely different behavior compared to the other two powders. CR15-3.3 presents a plateau in density curve at high temperature and shows a sharp decrease in densification curve after the peak temperature $\left(\sim 1450{ }^{\circ} \mathrm{C}\right)$.

It's possible to notice the bump in Figs. 5 and 6 . The bump at about $1150{ }^{\circ} \mathrm{C}$ was still present: The one for CR30-3.3 was bigger than the one present in CR30- 1 curve. The bump was also present in CR15 though very small, even smaller than the one for CR30-1.

An aspect that must be discussed separately from the points above is the CR15-3.3 behavior: after reaching the maximum value in the densification rate curve, the speed collapses to almost zero very quickly. To understand this behavior, the experiment was repeated on another pellet sample to see if some errors occurred on the dilatometer. The same conditions were used to replicate the experiment. The comparison between CR153.3 and the replicate (coded CR15-3.3(2)) is shown in Fig. 7. As can be seen from the graphs, curves display the same behavior and also the results obtained about the final density were the same. In both samples there was still a little bump. According to the plateau in the density curve, densification almost stopped after nearly $1450{ }^{\circ} \mathrm{C}$ and probably coarsening mechanism dominated sintering.

The densification and densification rate curves with respect to temperature for $6.6^{\circ} \mathrm{C} / \mathrm{min}$ are plotted in Fig. 8. As was expected, the results achieved were again lower than the previous ones and also the densities were similar to the precedents: the highest value 


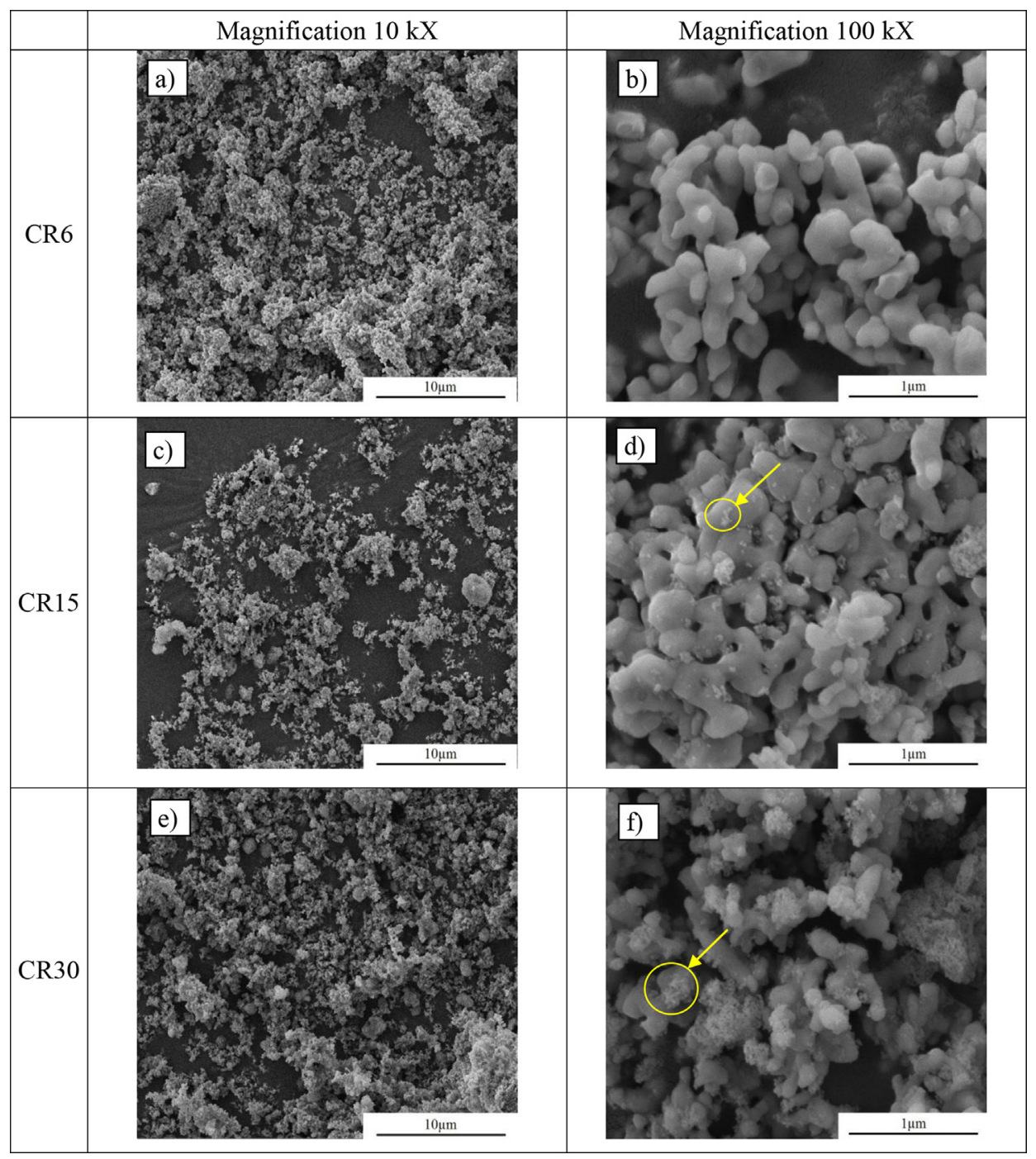

Fig. 3. Comparison of SEM images for the three different powders at different magnifications.

was obtained by CR15-6.6 while CR30-6.6 and CR6-6.6 have achieved lower densities but at values very close to each other. CR306.6 presented the same bump at about $1100^{\circ}-1200^{\circ} \mathrm{C}$, as the CR30 sample already discussed, but seemed to be bigger.

The formation of $\alpha$-alumina via transition aluminas $(\gamma)$ occurs by a nucleation and growth process during heating. The nucleation step depends on the heating rate; the number of nucleation sites increases with increasing heating rate [5]. The explanation is consistency with our dilatometric results (in Figs. 5, 6 and 8) that faster

Table 4

The particle sizes of the powders as measured from SEM images.

\begin{tabular}{llll}
\hline & CR6 & CR15 & CR30 \\
\hline Average particle size $(\mu \mathrm{m})$ & $0.7 \pm 0.2$ & $0.5 \pm 0.1$ & $0.6 \pm 0.2$ \\
\hline
\end{tabular}

Table 5

Average particle size comparison among the different techniques.

\begin{tabular}{llll}
\hline & CR6 & CR15 & CR30 \\
\hline Sedigraph $\mathrm{D}_{50}(\mu \mathrm{m})$ & $0.58 \pm 0.01$ & $0.42 \pm 0.01$ & $0.48 \pm 0.01$ \\
SEM $(\mu \mathrm{m})$ & $0.7 \pm 0.2$ & $0.5 \pm 0.1$ & $0.6 \pm 0.2$ \\
Technical schedule $\mathrm{D}_{50}(\mu \mathrm{m})$ & 0.6 & 0.4 & 0.4 \\
\hline
\end{tabular}

heating rates (3.3 and $6.6{ }^{\circ} \mathrm{C} / \mathrm{min}$ ) have higher gamma transformation peaks than low heating rate of $1^{\circ} \mathrm{C} / \mathrm{min}$.

\subsection{Microstructures of alumina ceramics}

SEM images of polished and thermally etched surfaces of sintered alumina ceramics are shown in Figs. 9 and 10. The microstructure results confirmed the Archimedes density results and according to the images, when the heating rate increased from $1{ }^{\circ} \mathrm{C} / \mathrm{min}$ to $3.3{ }^{\circ} \mathrm{C} / \mathrm{min}$, final density decreased. When the content of $\gamma$-phase was increased to more than $10 \%$, the faceted pores increased due to the formation of a pore colony, as shown in Fig. 10.

Table 6

Designation of the powder samples and heating rates.

\begin{tabular}{lllll}
\hline \multirow{5}{*}{} & \multicolumn{4}{l}{ Heating rate } \\
\cline { 3 - 5 } & & $1^{\circ} \mathrm{C} / \mathrm{min}$ & $3.3^{\circ} \mathrm{C} / \mathrm{min}$ & $6.6{ }^{\circ} \mathrm{C} / \mathrm{min}$ \\
\hline \multirow{2}{*}{ Type of alumina } & CR6 & CR6-1 & CR6-3.3 & CR6-6.6 \\
& CR15 & CR15-1 & CR15-3.3 & CR15-6.6 \\
& CR30 & CR30-1 & CR30-3.3 & CR30-6.6 \\
\hline
\end{tabular}


Table 7

Archimedes test results for samples.

\begin{tabular}{lllll}
\hline \multirow{5}{*}{ Heating rate } \\
\cline { 3 - 5 } & & $1{ }^{\circ} \mathrm{C} / \mathrm{min}$ & $3.3^{\circ} \mathrm{C} / \mathrm{min}$ & $6.6^{\circ} \mathrm{C} / \mathrm{min}$ \\
\hline \multirow{2}{*}{ Type of alumina } & CR6 & $93.5 \%$ & $89.4 \%$ & $89.9 \%$ \\
& CR15 & $94.2 \%$ & $93.2 \%$ & $91.2 \%$ \\
& CR30 & $92.8 \%$ & $91.9 \%$ & $89.4 \%$ \\
\hline
\end{tabular}

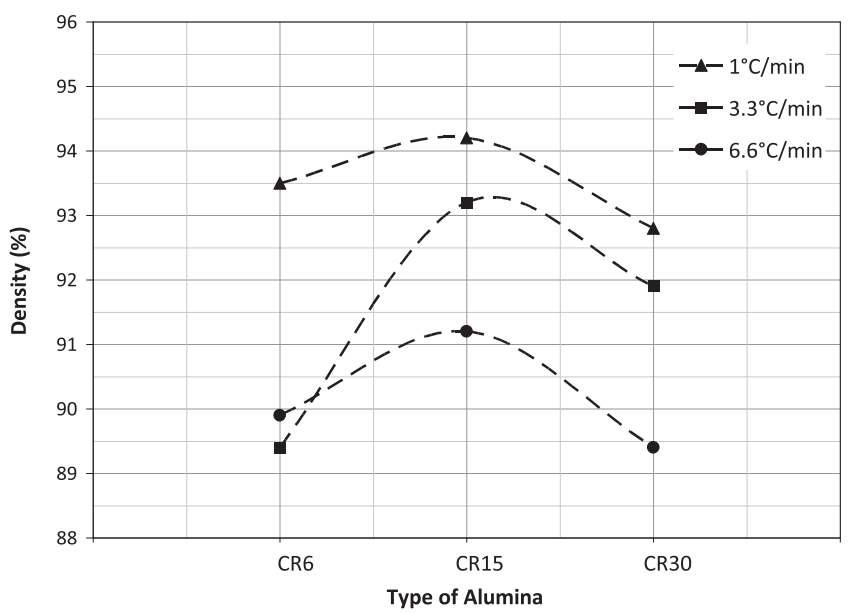

Fig. 4. Final density of alumina powders for three different heating rates.

The grain size was roughly measured from polished and thermally etched surfaces of sintered alumina ceramics. The results are shown in Fig. 11. According to the results, the grain size was not changed with the content of the $\gamma$-phase. On the contrary, as expected, the heating rate effects the grain size by keeping the sample at high temperatures for longer periods. The final result was CR6-1 had the biggest grain size among all samples.

A densified ceramic produced from these powders would be expected to show different mechanical properties. A discussion of these differences would be helpful but is not in the scope of this study. Gamma to alpha transition may result in the presence of pores in the ceramic if the transition is incomplete.

\section{Conclusions}

Three different commercially available alumina samples were sintered in a vertical dilatometer to see how they behaved as

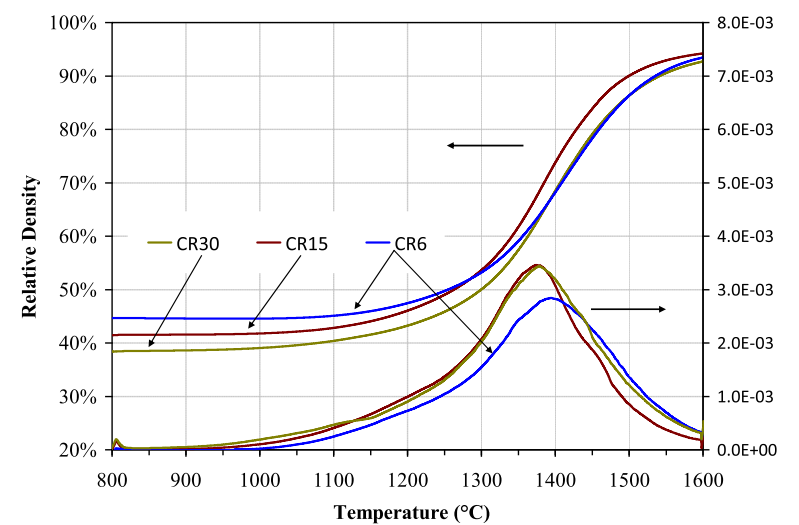

Fig. 5. Relative density and densification rate curve for alumina CR6, CR15 and CR30 during sintering at a heating rate of $1{ }^{\circ} \mathrm{C} / \mathrm{min}$.

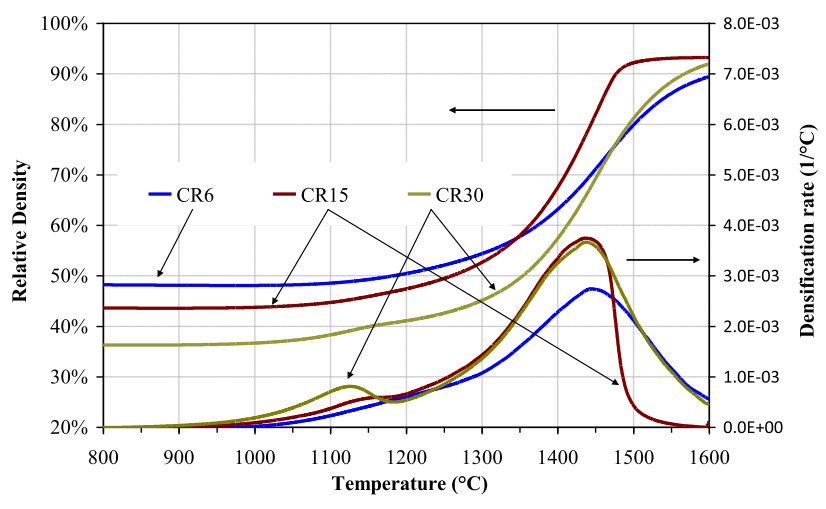

Fig. 6. Relative density and densification rate curve for alumina CR6, CR15 and CR30 during sintering at a heating rate of $3.3^{\circ} \mathrm{C} / \mathrm{min}$.

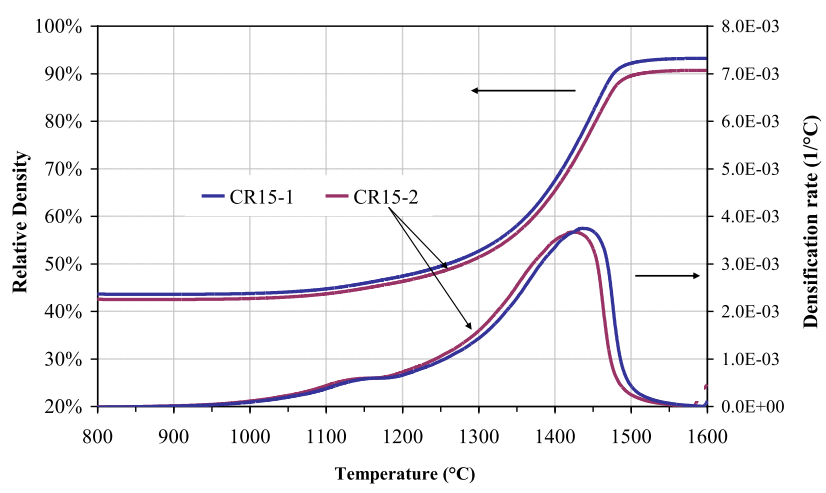

Fig. 7. Relative density and densification rate curve of CR15-3.3 and CR15-3.3(2) alumina samples during sintering at a heating rate of $3.3^{\circ} \mathrm{C} / \mathrm{min}$.

function of temperature. These powders were originally produced as dual phase materials consisting of $0 \%$ (CR6), 10\% (CR15) and $20 \%$ (CR30) gamma alumina the balance being alpha alumina. In the densification rate curves a bump was observed at around $1150{ }^{\circ} \mathrm{C}$ on the $10 \%$ and $20 \% \gamma$-phase content aluminas. The height of bump depends on the $\gamma$-phase content. When the $\gamma$-phase content was increased from $10 \%$ to $20 \%$, the bump height was also found to increase. The reason of this bump is the transformation of $\gamma$-phase to

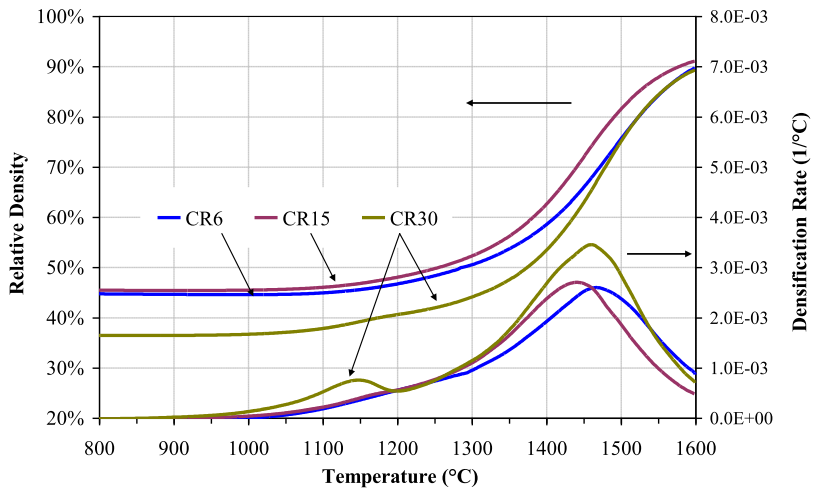

Fig. 8. Relative density and densification rate curve for alumina CR6, CR15 and CR30 during sintering at a heating rate of $6.6{ }^{\circ} \mathrm{C} / \mathrm{min}$. 

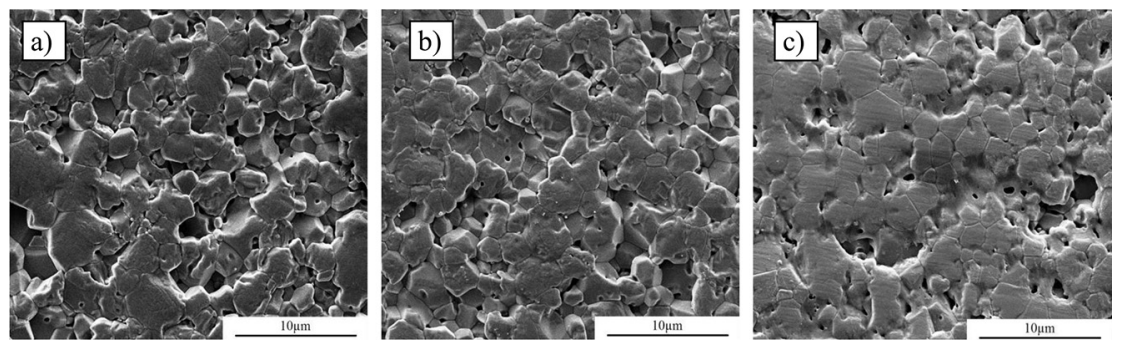

Fig. 9. Comparison of the microstructures of a) CR6, b) CR15 and c) CR30 alumina after sintering at $1{ }^{\circ} \mathrm{C} /$ min heating rate up to $1600{ }^{\circ} \mathrm{C}$.
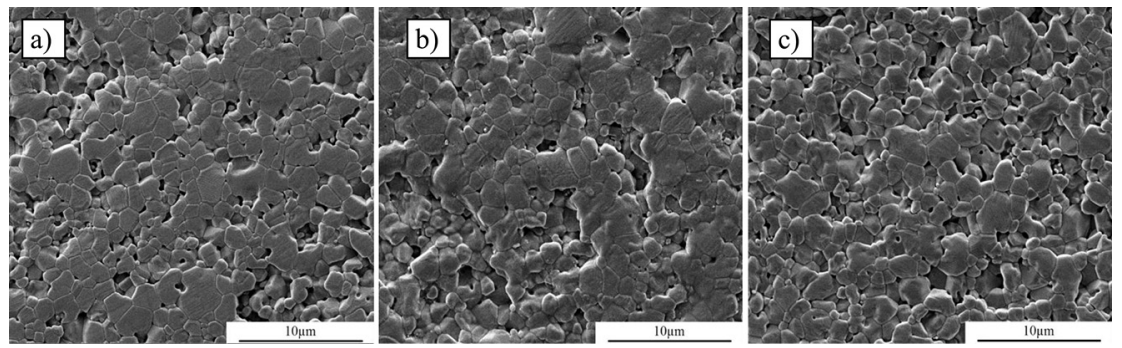

Fig. 10. Comparison of the microstructures of a) CR6, b) CR15 and c) $\mathrm{CR} 30$ alumina after sintering at $3.3{ }^{\circ} \mathrm{C} / \mathrm{min}$ heating rate up to $1600{ }^{\circ} \mathrm{C}$.

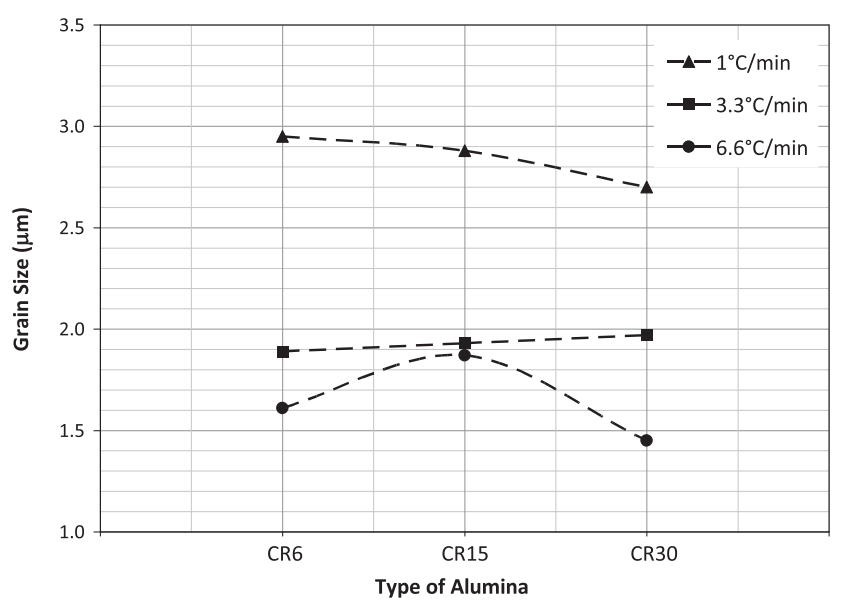

Fig. 11. Grain sizes of sintered alumina compacts at three different heating rates.

$\alpha$-phase. Again please note that no gamma alumina addition was done in this study. Only three samples were studied.

The formation of plateau on the density curve of the $10 \% \gamma$ phase alumina at $3.3^{\circ} \mathrm{C} / \mathrm{min}$ heating rate was observed and this phenomenon was not observed in the other heating rates and the other aluminas.
The density of alumina powder with $10 \%$ gamma phase was found to increase independent of the heating rate. But when an alumina powder with higher proportion of gamma phase was sintered the density was found to slightly decline. Grain size was not significantly affected by the $\gamma$-phase content.

\section{Acknowledgement}

The authors are grateful to IYTE-MAM staff for their help and technical supports.

\section{References}

[1] K. Wefers, C. Misra, Oxides and Hydroxides of Aluminum, ALCOA Technical Paper No. 19, Rev. ALCOA Labs, 1987.

[2] X. Yang, A.C. Pierre, D.R. Uhlmann, J. Non-Cryst. Sol. 100 (1988) 331, http:// dx.doi.org/10.1016/0022-3093(86)90142-0.

[3] F.W. Dynys, J.W. Halloran, J. Am. Ceram. Soc. 65 (9) (1982) 442, http:// dx.doi.org/10.1111/j.1151-2916.1982.tb10511.x.

[4] C.S. Nordahl, G.L. Messing, J. Eur. Ceram. Soc. 22 (2002) 415. http://dx.doi.org/ 10.1016/S0955-2219(01)00285-0.

[5] C. Legros, C. Carry, P. Bowen, H. Hofmann, J. Eur. Ceram. Soc. 19 (11) (1999) 1967, http://dx.doi.org/10.1016/S0955-2219(99)00016-3.

[6] C.S. Nordahl, G.L. Messing, Thermochim. Acta. 318 (1998) 187, http://dx.doi.org/ 10.1016/S0040-6031(98)00343-8.

[7] E. Sato, C. Carry, J. Am. Ceram. Soc. 79 (8) (1996) 2156, http://dx.doi.org/10.1111/ j.1151-2916.1996.tb08950.x.

[8] S.-W. Kim, S.Y. Kim, Solid State Phenom. 124-126 (2007) 831, http://dx.doi.org/ 10.4028/www.scientific.net/SSP.124-126.831.

[9] Baikowski, Spinel Technical Information Data for Alumina and Spinel, 2010. http://www.baikowski.com (accessed 10.03.10). 